\title{
Evaluation Research on Production Safety of Riot Bombs Based on Unascertained Measure
}

\author{
Tong Wang ${ }^{1, a^{*}}$ and Kuang Sheng Xie ${ }^{2, b}$ \\ ${ }^{1}$ College of Equipment Engineering, Engineering University of CAPF, Xian, China \\ ${ }^{2}$ College of Equipment Engineering, Engineering University of CAPF, Xian, China \\ a478906530@qq.com, ${ }^{b}$ xiekuan_cn@sina.com
}

Keywords: The production of riot bombs; Unascertained measure; Evaluation research on production safety

\begin{abstract}
Aimed at the uncertainty of safety risks in the production process of riot bombs, based on the analytical study of various factors, has put forward the evaluation method of unascertained measure mathematical model, established the comprehensive evaluation index system with production safety as the core, and evaluated the production safety of riot bombs. The model evaluation index can be selected flexibly according to the actual situation, with comprehensive and targeted features. The assessment reveals a positive results, it has certain reference value to the safety production of riot bombs.
\end{abstract}

\section{Foreword}

Since the invention of non-lethal weapons, it is played an irreplaceable role in the process of the disposal of riots. Riot bomb is one of the most commonly used non-lethal weapons in the disposal of riots. It is species diversity, simple structure and the low level of production technology made it functional. The hand type, gun hairstyle and on-board emission type is the most common three kinds of riot. After launch, riot bomb needs through explosive burning explosion which will send tear agent, dyeing agent and kinetic energy. The use of explosive made the production process has some danger. Therefore, to evaluate the safety of the riot bombs production, we can put up around the production workshop and around the table with sand retaining wall, concrete rigid retaining wall, water blast walls and precast concrete retaining wall plate, etc $[1,2]$. All of these, it has theoretical practical significance.

At present domestic has a variety of evaluation methods about the weapon's production and use, and the theoretical models are mature. Because of the uncertainty of the factors in the process of production, this paper chose to measure unknown mathematical model applied to the safety assessment of the riot production, with the theory of entropy weight method to determine the index weight and the confidence identification criterion degree of credibility evaluation results, the uncertainty factor index had good treatment and presentation.

\section{Set Up Index System}

There are many factors influencing the riot production safety. Generally speaking, the reliability of the black powder, production equipment and production environment factors are the main three aspects. Through the study of the production workshop, combined with relevant experts' guidance, and in total consideration the factors that affect the riot production security, We selected 9 evaluation indexes in this paper, where the safety assessment is carried on the safety evaluation, and the evaluation index system is set up [3], as shown in Fig. 1: 


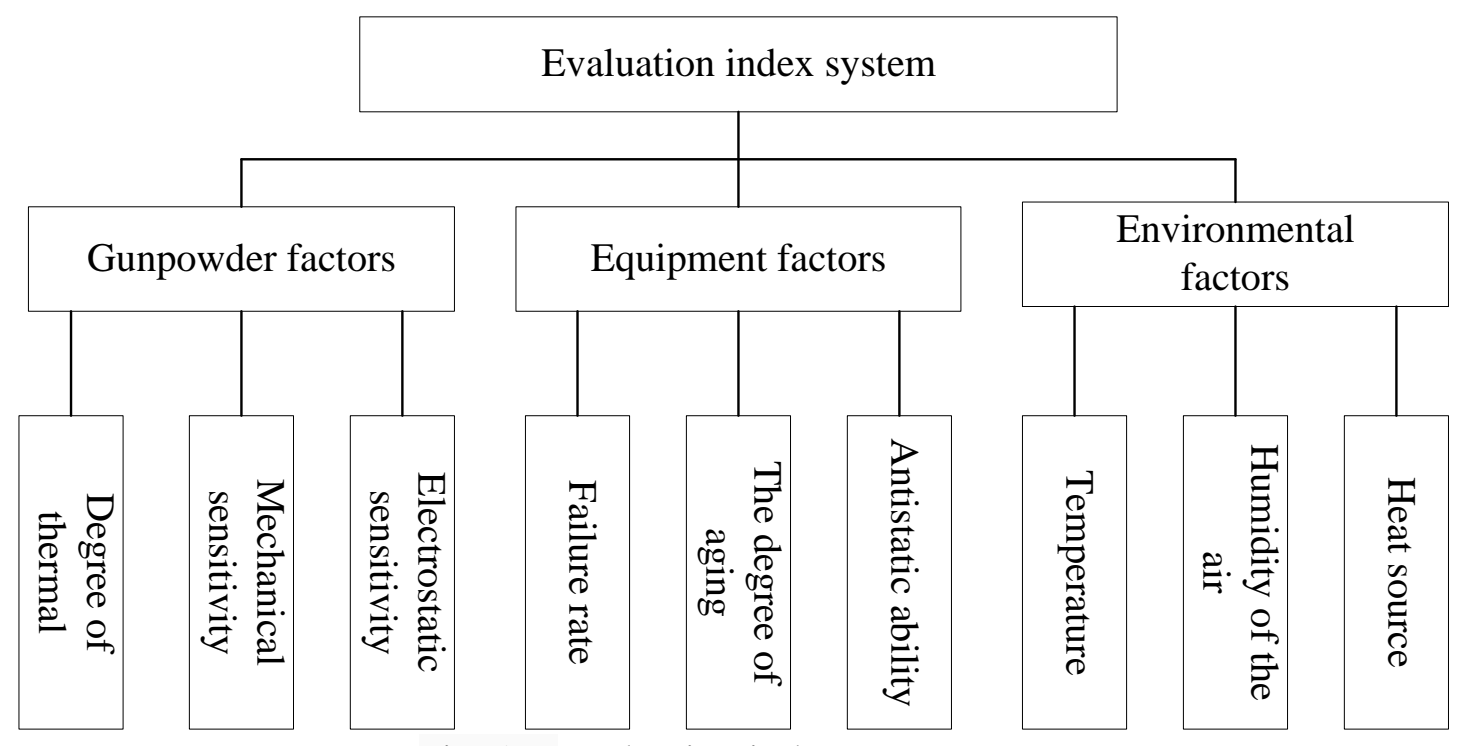

Fig. 1 Evaluation index system

The Reliability of The Black Powder. The reliability of the black powder factors mainly include thermal, mechanical sensitivity and static inductance degrees, all of these are based on the characteristic of black powder to evaluate.

Thermal degree refers to the sensitivity of black powder under the action of heat, often said with a breaking point. It is impacted with the time of heating, the heating method and the heating speed, In general, the higher of the temperature, the easier to ignite.

The mechanical sensitivity includes the impact sensitivity and friction sensitivity, which is the black powder's sensitivity in the impact and friction. Black powder would collision and friction in the process of handling, loading. So the mechanical sensitivity is an important index of reliability evaluation of black powder.

Static inductance degrees including black powder friction to the difficulty of the static electricity, and the electrostatic spark discharge under the action of the sensitive degree of explosion, that is to say, the cumulative value of electrostatic and spark sensitivity. When static electricity petard is large enough, it causes black powder explosion to make safety accident [4].

The Equipment Factors. Production equipment is the platform of the riot production. Equipment safety has a direct impact on the quality of production. We select fault rate, aging degree and antistatic ability as evaluation index of production equipment reliability.

Failure rate is the production of equipment failure. It can be used to shutdown time in the percentage of the equipment should work time. Failure rate is an index to measure equipment failure strength, technical state and efficiency.

Aging is refers to the production equipment in the process of long-term use, storage or idle, Because of parts vibration, friction, corrosion, which impacts machines loss of working ability and the accuracy of reliability. Generally speaking, the more time of the equipment severe, the lower reliability it is.

Electrostatic is common phenomenon in nature, the ability of the production equipment to evacuate electrostatic antistatic and block electrostatic, the stronger it is, the higher its reliability.

The Environment Factors. There are many factors of production environment. We only select production effect of the three largest, environmental temperature, air humidity and heat source.

The change of environmental temperature could cause ammonium nitrate explosive's crystal shape changed, even lead to the grain size in extrusion. On the one hand, the pressure increases would affect the grain chemical stability. On the other hand, it may lead to the failure of drug. Therefore, the higher the production operation environment temperature is, the more unfavorable to riot's safety production [5].

Air humidity will affect ammunition in charge in metamorphic, metal's rusting, rubber components 
and material aging make the projectile deformation. All of these cause the loss of projectile and reduce the protection function [6].

Preparation of heat source such as electric heater, fireworks, soldering iron is the possibility of ignition ammunition, which also affect the safety in production.

\section{Comprehensive Evaluation}

The Comprehensive Evaluation System. To determine both the accuracy of the safety assessment of comprehensive value evaluation object, and to reducing the uncertainty when evaluation value determined, this paper is based on information entropy model of unascertained measure evaluation $[7,8]$.

Set $u_{i j}$ to measure single index matrix of evaluation objects:

$$
u_{i j}=\left(\begin{array}{ccc}
u_{11} & \ldots & u_{1 j} \\
\vdots & \ddots & \vdots \\
u_{i 1} & \cdots & u_{i j}
\end{array}\right)
$$

Next is the index weight calculation steps, make

$$
\begin{aligned}
& L(u)=-\sum_{j=1}^{j} u_{i j} \cdot \ln u_{i j} \\
& v_{i}=1-\frac{1}{\ln j} L(u)=1+\frac{1}{\ln j} \sum_{j=1}^{j} u_{i j} \cdot \ln u_{i j}
\end{aligned}
$$

Normalization is handled:

$$
w_{i}=\frac{v_{i}}{\sum_{i=1}^{i} v_{i}}
$$

$w_{i}\left(0 \leq w_{i} \leq 1\right.$, and $\left.\sum_{i=1}^{i} w_{i}=1\right)$, as for the weight of each evaluation index evaluation object. Make $W=\left(w_{1}, w_{2}, w_{3}, \ldots w_{i}\right)$ as evaluation object corresponding to the evaluation index weight vector.

According to the unascertained measurement of the indicators and the corresponding weights of the calculation results, we can get comprehensive evaluation results of the evaluation object. Write $c_{j}$ to be comprehensive evaluation result evaluation object to be comprehensive evaluation result evaluation object in the $\mathrm{j}$ grade evaluation grades of unascertained, we get

$$
c_{j}=W \cdot u_{i j}=\left(w_{1}, w_{2}, w_{3}, \ldots w_{i}\right) \cdot\left(\begin{array}{ccc}
u_{11} & \ldots & u_{1 j} \\
\vdots & \ddots & \vdots \\
u_{i 1} & \cdots & u_{i j}
\end{array}\right)
$$

$C=\left(c_{1}, c_{2}, c_{3}, \ldots c_{j}\right)$ is a comprehensive evaluation measure for objects vector. It is to show the significance of the evaluation objects in the uncertain degree of each evaluation class. To get a degree result, we need to identify the degree of confidence. Because of the evaluation grade partition is ordered. The $\mathrm{j}$ estimation scale $\mathrm{c}_{\mathrm{j}}$ grades is better than the $j+1$ level evaluation $\mathrm{c}_{\mathrm{j}+1}$, So we can't use the largest measure recognition criteria. Here we use the confidence identification [9]. Set $\lambda$ as the degree of confidence, $(\lambda \geq 0.5)$,we usually take 0.6 or 0.7 . The calculation model of confidence 
recognition criteria are as follows:

$$
\mathrm{j}_{0}=\min _{\mathrm{j}}\left\{\mathrm{j}: \sum_{\mathrm{j}=1}^{\mathrm{j}} \mathrm{c}_{\mathrm{j}} \geq \lambda, \quad \mathrm{j}=1,2,3, \ldots \mathrm{j}\right\}
$$

Get $\mathbf{J}$ until it fit the formula Eq.5, the comprehensive evaluation results of the evaluation object for the grade of $j_{0}$ evaluation grades $c_{j}$.

The Comprehensive Assessment of Riot Production Safety. We have established the evaluation index system, in front of each evaluation index is divided into five levels of evaluation, through the expert scoring, the results of statistics as shown in the Table 1 below:

Table 1 Experts scoring results

\begin{tabular}{llcccc}
\hline \multicolumn{1}{c}{ Rating } & $\begin{array}{c}\text { Very } \\
\text { good }\end{array}$ & Good & Medium & General & Poor \\
\hline $\begin{array}{l}\text { Degree of } \\
\text { thermal }\end{array}$ & 10 & 45 & 30 & 10 & 5 \\
$\begin{array}{l}\text { Mechanical } \\
\text { sensitivity }\end{array}$ & 60 & 20 & 15 & 3 & 2 \\
$\begin{array}{l}\text { Electrostatic } \\
\text { sensitivity }\end{array}$ & 70 & 18 & 7 & 4 & 1 \\
Index & 45 & 37 & 13 & 3 & 2 \\
$\begin{array}{l}\text { Failure rate } \\
\text { The degree of }\end{array}$ & 40 & 25 & 25 & 7 & 3 \\
$\begin{array}{l}\text { Aning } \\
\text { ability }\end{array}$ & 65 & 20 & 8 & 4 & 3 \\
Temperature & 54 & 25 & 15 & 4 & 2 \\
$\begin{array}{l}\text { Humidity of } \\
\text { the air }\end{array}$ & 48 & 22 & 16 & 10 & 4 \\
Heat source & 30 & 35 & 20 & 10 & 5 \\
\hline
\end{tabular}

By above grade as a result, the unascertained measurement evaluation matrix of a single index: $\mathrm{u}_{\mathrm{ij}}=$ $\left[\begin{array}{lllll}0.10 & 0.45 & 0.30 & 0.10 & 0.05 \\ 0.60 & 0.20 & 0.15 & 0.03 & 0.02 \\ 0.70 & 0.18 & 0.07 & 0.04 & 0.01 \\ 0.45 & 0.37 & 0.13 & 0.03 & 0.02 \\ 0.40 & 0.25 & 0.25 & 0.07 & 0.03 \\ 0.65 & 0.20 & 0.08 & 0.04 & 0.03 \\ 0.54 & 0.25 & 0.15 & 0.04 & 0.03 \\ 0.48 & 0.22 & 0.16 & 0.10 & 0.04 \\ 0.30 & 0.35 & 0.20 & 0.10 & 0.05\end{array}\right]$

By the formula Eq.2, Eq.3, calculate the weight of each index:

$\mathrm{W}=(0.0767,0.1412,0.1899,0.1193,0.0711,0.1572,0.1207,0.0748,0.0492)$

Calculated by the formula (4) comprehensive evaluation vector is:

$\mathrm{C}=\left(\begin{array}{lll}0.5255,0.2541,0.1433,0.0516, & 0.0257)\end{array}\right.$

Take confidence as $\lambda=0.7$, by the confidence level identification criterion formula Eq.5 to calculate when $\mathrm{j}=2$, satisfied

$\mathrm{j}_{0}=\mathrm{c}_{1}+\mathrm{c}_{2}=0.5255+0.2541=0.7>\lambda=0.7$

So, the result of riot production safety evaluation fit the second grade, notes for the "good". The 
evaluation method considering the order and hierarchy, and the weights according to the calculated is objective. The comprehensive evaluation results are confidence identification criterion rating and evaluation results are consistent with actual situation, it is the simplicity of the rationality of the evaluation and calculation. Above characteristic is better than grey correlation evaluation method, fuzzy number of entropy method and analytic hierarchy evaluation method.

\section{Conclusion}

According to the riot, such as production equipment and production environment influence the safety conditions of riot bombs production, we give 9 indexes as powder of thermal, mechanical sensitivity, static inductance degrees, equipment failure rate, aging degree, antistatic ability, production environment temperature, air humidity and heat source. The selection of indicators through the comprehensive consideration, they have certain representativeness.

Due to the uncertainty of each evaluation index, using the theory of entropy weight method to determine the weight of each index, the weight of each index can be provided by the object observations about index classification information is obtained by calculation. As a result, it avoids the fuzzy hierarchy evaluation method and avoids grey relational evaluation method of deficiencies. It uses confidence identification criteria to determine the comprehensive evaluation results. All of these make the evaluation results more objective and avoid the subjective effect.

It uses the unascertained measurement mathematical model to assessment the production safety of riot bombs. The evaluation process is simple and the result of evaluation accords fit the actual. For the safety evaluation of riot bombs production, it has certain reference significance and representative. Not only for other non-fatal ammunition's manufacturing provides a new train of thought, but also to provide certain theoretical for install protective wall protection measures in the workshop.

\section{References}

[1] D. Bogosian, D. Piepenburg. Proceedings of the 17th International Symposium on the Military Aspects of Blast and Shock.( Las Vegas,Nevada,2002).

[2] P.K. Bowles. Proceedings of the 11th International Symposium on Interaction of the Effects of Munitions with Structure.(Germany,2003).

[3] D.J Gong, S.X. Guo, H.Y. Qin. Journal of Liaoning Engineering Technology University (Natural Science Edition), Vol.33 (2014) No.1,p.107-111. (In Chinese)

[4] J.C. Xia and L. Liu etc. Initiating Explosive Device Manufacturing (Beijing University of Science and Technology Press. China. 2009).p.20 to 24. (In Chinese)

[5] B. Liang and J.Z. Yi etc. Journal of Sichuan Armaments Factories, Vol.29 (2008), No.1. (In Chinese)

[6] S.J. Tang. Journal of Hubei Institute of Technology, Vol.33 (2013) No7. (In Chinese)

[7] F. Hai, X.M. Wang and L. Wang. Journal of Fire Command and Control, Vol.38 (2013),No.6.p. 93-101. (In Chinese)

[8] T.J. Tao and G.Z. Wang. Journal of Engineering Blasting. Vol.19 (2012), No.2. p.22-25. (In Chinese)

[9] H.G. He, S.G. Su etc.. Journal of Central South University (Natural Science Edition), Vol. 44. (2013). No.4, p.1564-1570. (In Chinese) 